\title{
On the Influence of the Propaganda of Marxism through Li Dazhao's Practice in Peking University Library and Its Contemporary Enlightenment
}

\author{
Ying Wang \\ Zhejiang University, China Zhejiang Hangzhou 310007 \\ wing8939@126.com
}

\begin{abstract}
Keywords: Li Dazhao, Peking University Library, the Propaganda of Marxism; Contemporary Enlightenment.
\end{abstract}

\begin{abstract}
The appointment and practice of Peking University Library is a key experience for Li Dazhao to turn into a Marxist. The development course of Peking University Library is also the process that Li Dazhao's self-consciousness has been improved rapidly, his cognition and propaganda of Marxism has been expanded in depth over the same period. During his tenure, he made great efforts to promote the modern transformation of the Peking University Library and made Peking University a platform for the dissemination of Marx doctrine. The Peking University Library had changed from "a borrowing place" to "a research room" and provided the important content of the research and dissemination of Marx doctrine. He also took the library as a base to influence young intellectuals, and further expanded the influence of Marx's dissemination. The contemporary library undertaking of China should be guided by Marxism, hold fast to the masses standpoint. The public libraries should play propulsive role as a carrier to boost the popularization of Marxism. In addition, school libraries should serve as important position for improving the literacy of young Marxist.
\end{abstract}

\section{Introduction}

The essay of The mourning for comrade Li Dazhao on $195^{\text {th }}$ Guide Weekly on May 8, 1927 and then the publish of May 4th and Li Dazhao by Republic Daily in Hankou on the day of May 24th, was for the start of the study and commemoration of Li Dazhao. For 90 years, relevant research field continues to expand and historical data has been continuously enriched. Recalling his brief but extraordinary life, from early 1918 to 1922 at the Peking University as the director of the library, was an important period of life to Li Dazhao, the transition period of Peking University Library, and also a critical period of advancing the course of history. As the proletarian revolutionist who took the lead in lifting the banner of Marxism in China, Li Dazhao's influence on the spread of Marx doctrine in China is multi-channel, multi-level and multifaceted, especially took the Beijing University Library as the base, and had an important impact on the subsequent revolutionary activities.

From 1990s, Li Dazhao's contribution to the construction of advanced culture has drawn great attention from the academic fields (Wu 2006). Existing research focuses on the introduction of the specific reforms and practice by Li Dazhao in Peking University Library. However the relationship between his experience of being a library director and during this period rapidly turned into Marxist is yet to be studied. Also, how did he spread the Marx doctrine actively in the library and promote the popularization of Marx's theory should be further studied. Compare to his previous editor's identity, working on the library made it easier to obtain abundant research material and closer to communicate with readers. The position of library director made his social contact more convenient and wider. Later, the change of identity of Peking University Professor strengthened his influence in the youth, and laid the groundwork for later to guide the intellectuals and the working class to join the revolutionary movement. The development process of Peking University Library is also the process of Li Dazhao's self-consciousness rapidly raised. His understanding and propaganda of 
Marx doctrine had deepened during the same period. Therefore, we should study and value the impact of this experience on the spread of the Marx doctrine in China and on himself. Li Dazhao's library activity is a vivid embodiment of Marxist practical and mass viewpoints, and also a good example of the combination of theory and practice in library field. This paper is an attempt to study Li Dazhao library practice, is also back to history, from the past to the future, looking for inspiration for the contemporary China to take library as a carrier to promote the popularization of the Marx doctrine.

\section{Li Dazhao took the Peking University Library as the front and spread Marx doctrine earliest in China}

\subsection{Promote the modern transformation of Peking University Library, and make Peking University become the dissemination platform of Marxism}

During his tenure, Li Dazhao contributed to the modern transformation of Peking University Library from semi-closed to open. By setting up newspaper reading room, teacher reading room, special reading room, the library introduced the progress books of Marxism and the October Revolution, and provided guidance and new book recommendations through The Journal of Peking University, and used the anniversary to carry out activities and expanded the propaganda of Marxism. The modern library has changed the situation of attaching importance to the collection more than the utilization, and provided favorable conditions for the study, research and exchange of Marxist theory. It can be said that the Marxist tradition of Peking University was created and extended from the library's director Li Dazhao. When the Beijing communist group was established in October 1920, its members were all teachers and students of Peking University. By July 1921, before the formal establishment of the communist party of China, there were 12 members of the communist party of Beijing, 10 of whom were teachers and students of Peking University on the influence of Li Dazhao (Sha 1998). The Peking University Library and the whole university had become an important platform for spreading Marxism.

\subsection{Make the Peking University Library change from "a borrowing place" to "a research room", and provide the important content of Marxism research and dissemination}

The thought of "library is the research laboratory" runs through the practice of Li Dazhao's term of office. The Public Notice of Library's Director of The Journal of Peking University has mentioned many similar references, such as "for academic reference" and "benefit to the students ". He actively expanded the collection resources and improved the collection structure. According to Luo Longzhang, Peking University has a large number of new published western instruments. It can be said that Peking University was the place where the Chinese universities had large number of progressive books. He also actively organized the translation work, and translated the literature about socialism in the most concise way, and further studied the relationship between China and socialism and the methods of its implementation. Li Dazhao's communist belief largely came from the logical strength and the charm of the Marxist theory which he felt. It should be said that Li Dazhao truly study, research and accept of Marxism began in the university library, his series of introduction and propaganda of the October Revolution and the important political theory of Marxism began and focused on this period, such as Comparative views of French and Russian Revolutions, The Common People's Victory, Bolshevism's Victory, My Views on Marxism, Socialism in China and Capitalism in the World and so on. In this period, he also experienced the process from the comparison to the choice, from the study to the research, from the introduction to the dissemination, from the theoretical research to the concrete practice.

\subsection{Taking Library as the base to influence young intellectuals and expanding the influence of Marxism}

Li Dazhao, a young tutor, paid special attention to interact with intellectuals. He actively explored and promoted Marx doctrine with teachers and students, making Peking University 
Library become important social communication spaces. Many of the progressive young intellectuals have come here (the university library) to seek the truth, they either diligently study or jointly research and exchange, or go straight to Li Dazhao and consult with him (Yin 1996). He also vacated a room in the library as a social pavilion for the found of the new Trend magazine by Fu Sinian and Luo Jialun. In the contact with the intellectuals in the library, Li Dazhao cultivated the strong revolutionary will and noble moral sentiments by influencing the progressive youth. Mao Zedong called Li Dazhao "the real teacher ". In December 1918, when Mao Zedong worked in the Peking University Library as an assistant, Li Dazhao often communicated with him and introduced him to the Young Chinese Society. To record in the Snow's book Red Star over China, "in the summer of 1920, in theory, to a certain extent also in action, I became a Marxist”(Snow 1979). Li Dazhao initiated the combination of Marxism and the concrete reality of China, and played an important role in the formation of Mao Zedong thought. In addition, a large number of young people, such as Deng Zhongxia, Zhou Enlai, Deng Xiaoping, Chen Yi, Gao Junyu, He Mengxiong and Chen Qiaonian, turned to Marxism under the influence of Li Dazhao. After the transformation as a professor, Li Dazhao taught a series of Marxist theoretical courses, and developed young people in the teaching process, such as Socialism, Research on Historical Materialism, Socialism and Social Movement and so on to formally put Marxism theory into the university teaching courses for the first time. He also systematically publicized Marx doctrine combined with historical work, and made important contributions to the dissemination and research of historical materialism. He hoped that the intelligentsia should be the pioneer of the masses, and that the masses should be the backing of the intelligentsia. He called for young students who believe in Marxism Leninism to go with the masses of workers and peasants, and to work among workers, peasants and working women. Under the efforts of Li Dazhao and others, scientific socialism was spread from intellectuals to the workers and peasants, and the development of socialist thought entered a new stage in china.

\section{Li Dazhao's Contemporary Enlightenment of spreading Marx doctrine with the library as the front}

\subsection{The library undertaking should take Marxism as the guide and hold fast to the masses standpoint}

Only in the mass life and in practice can the vitality of Marxism be fully displayed. The library construction should meet the psychological and spiritual needs of the people, develop Marxism in the center of the most concern of the public, avoid the label and fictitious of Marxism, and make the basic value of Marxism into the cultural life of the people. It is impossible for the realization of socialism to leave the people themselves, and the mass standpoint is the key to test whether the library cause follows the Marx doctrine. The influence of Li Dazhao library practice is not only to increase people's intelligence, but also to change people's way of life and behavior, so that people can develop the habit of using the library. Public cultural institutions meet the needs of the public has become a consensus, how to make more people voluntary and actively use public cultural services is another important task after the continuous improvement of infrastructure. The quality of library services, the effectiveness of the construction of public cultural service system is decided by the people, the people are the real creators and practitioners. We should encourage people to actively participate in cultural activities, so that participation in cultural activities becomes a way of life, in a cultural way to infiltrate the Marxist connotation into the daily life of the people.

\subsection{Public library is an important carrier to promote the popularization of Marxism}

Library is one of the public cultural institutions with the highest frequency of public use, and undertakes the important task of publicizing Marxism and spreading advanced culture to the masses of the people. The library should provide an ideal platform for the whole people to learn Marxism, combine the rational development of library resources with the value concept of Marxism, 
effectively improve the affinity of Marxism, and highlight the charm of Marxist theory in the fresh daily situation. Marxism's literature resources should highlight localization and characteristics, and enhance the people's vicarious sense when they understand Marxism Theory. Different groups understand and accept Marxism theory in different ways, Marxism's exposition should strive to diversify, in order to adapt to the people's acceptance habits. We should create Marxism cultural space, carry out theme activities with lectures, exhibitions and mass participation, enhance intuitive, experiential and interactive, and extend the influence scope of Marx doctrine. The Marxist theory needs to be explained in plain language, to strengthen the library practitioners' Marxist literacy, build the volunteer service team and encourage the mechanism to guide people to correctly understand Marxism.

\subsection{School library is an important position to improve the Marxist literacy of young people}

The effectiveness of the popularization of Marxism depends on the existing conditions of the audience, and to win the public, we must win the young. School is an important battlefield in the field of ideological struggle. As an important component of supplementary education outside the classroom, school library should play a role in improving Marxism literacy of the youth. Li Dazhao's library reform has cooperated with the actual needs of teaching and scientific research, and promoted Beijing University to be a research university. In the spirit of facilitating the teaching and research, the modern school library should have a role in the construction of campus culture, combine the dissemination of Marxism with the education of youth outlook on life, pay attention to the patriotism education of young people, and keep the continuity of education. It is necessary to create a social interaction space for library to learn and inspire, encourage users to enter the library, and move the service forward, so that library services can be approached to the users.

\section{References}

[1] Hanquan Wu. The progress and related issues of Li Dazhao's research in the past 10 years [J]. Modern Chinese History Studies, 2006 (4) 146-157.

[2] The Whole Collection of Li Da-zhao [M]. Beijing: People's Publishing House, 2013 (3) 29-333.

[3] Sunjian Sha. Li Dazhao's Marxist view and the Marxist tradition of Peking University [J]. Journal of Peking University (Philosophy and Social Sciences), 199835 (2) 26-35.

[4] Qun Liu. Li Dazhao and Chinese modern library [J]. Library Work and Study, 2001 (6) 25-28.

[5] Gaochao Yin. Mao Zedong’s teachers [M]. Lanzhou: Gansu People's Publishing House, 1996 12.

[6] Edgar Snow, Red star over China [M]. Beijing: Sanlian Bookstore, 1979131.

[7] Xiaohui Wang, Discussion on Li Dazhao's Contribution to the Development of Modern Library System, Journal of Academic Libraries, 2010 (1) 115-125. 